Article

\title{
Adsorption and Diffusion of Xylene Isomers on Mesoporous Beta Zeolite
}

\author{
Aixia Song, Jinghong Ma *, Duo Xu and Ruifeng Li \\ Institute of Special Chemicals, School of Chemistry and Chemical Engineering, Taiyuan University of \\ Technology, Taiyuan 030024, China; E-Mails: songaixia0563@link.tyut.edu.cn (A.S.); \\ xdmany@163.com (D.X.); rfli@tyut.edu.cn (R.L.) \\ * Author to whom correspondence should be addressed; E-Mail: majinghong@tyut.edu.cn; \\ Tel./Fax: +86-351-601-0121.
}

Academic Editor: Andreas Martin

Received: 31 October 2015 / Accepted: 30 November 2015 / Published: 8 December 2015

\begin{abstract}
A systematic and detailed analysis of adsorption and diffusion properties of xylene isomers over Beta zeolites with different mesoporosity was conducted. Adsorption isotherms of xylene isomers over microporous and mesoporous Beta zeolites through gravimetric methods were applied to investigate the impact of mesopores inside Beta zeolites on the adsorption properties of xylene isomers in the pressure range of lower 20 mbar. It is seen that the adsorption isotherms of three xylene isomers over microporous and mesoporous Beta zeolites could be successfully described by the single-site Toth model and the dual-site Toth model, respectively. The enhanced adsorption capacities and decreased Henry's constants $\left(K_{\mathrm{H}}\right)$ and the initial heats of adsorption $\left(Q_{\mathrm{st}}\right)$ for the all xylene isomers are observed after the introduction of mesopores in the zeolites. For three xylene isomers, the order of Henry's constant is $o$-xylene $>m$-xylene $>p$-xylene, whereas the adsorption capacities of Beta zeolite samples for xylene isomers execute the following order of $o$-xylene $>p$-xylene $>m$-xylene, due to the comprehensive effects from the molecular configuration and electrostatic interaction. At the same time, the diffusion properties of xylene isomers in the mesoporous Beta zeolites were also studied through the desorption curves measured by the zero length column (ZLC) method at $333-373 \mathrm{~K}$. It turned out that the effective diffusion time constant $\left(D_{\text {eff }} / R^{2}\right)$ is a growing trend with the increasing mesoporosity, whereas the tendency of the activation energy is just the reverse, indicating the contribution of mesopores to facilitate molecule diffusion by shortening diffusion paths and reducing diffusion resistances. Moreover, the diffusivities of three xylene isomers in all Beta zeolites follow an order of $p$-xylene $>m$-xylene $>o$-xylene
\end{abstract}


as opposed to $\mathrm{KH}_{\mathrm{H}}$, conforming the significant effects of adsorbate-adsorbent interaction on the diffusion.

Keywords: adsorption; diffusion; mesoporous beta zeolite; xylene isomers

\section{Introduction}

Zeolites are typical microporous crystalline materials with narrow pore size distribution ranging from 0.3 to $1.5 \mathrm{~nm}$, having a widespread application in adsorption, separation, and catalysis with its unique properties, such as developed ordered porous structure, high specific surface area, and strong acidity, high hydrothermal and thermal stability [1-3]. Adsorption and diffusion of molecules in zeolites are very significant performances for understanding these processes of zeolite applications, especially the catalytic performance of chemical reaction over zeolites. However, adsorption and diffusion limitations are often observed when the processes involve large molecules [4]. To alleviate this, hierarchical porous materials have attracted a wide spread attention with the advantages of enhancing the mass transfer and improving the accessibility of the molecules in intracrystalline. There are different approaches to synthesize hierarchical zeolites. Among which, introducing mesopores into the original structure of microporous zeolites is one of the most efficient methods [5-7]. Such mesostructured zeolite materials have not only the advantages of micropores, which ensure acidity and shape selectivity, but also the advantages of mesopores, which promote the adsorption of molecules [8-10] and diffusion rate for mass transfer within zeolites [8,11-13].

As zeolite Beta has large window diameter and strong acidic sites, it has become a member of zeolitic materials of great substantial industrial importance, displaying unique catalytic reactivity in chemical reactions of hydrocarbons. Beta zeolite belongs to a complex intergrowth family, which consists of two (polymorph A and B) or more polymorphs [14]. It is a high-silica zeolite with three-dimension channel system and consists of straight ring channels of a free aperture of $0.76 \times 0.64 \mathrm{~nm}$ and zig-zag ring channels of $0.55 \times 0.55 \mathrm{~nm}$ which are similar to other large-pore molecular sieves such as FAU and EMT zeolites. Even Beta zeolite can be classified as a large pore zeolite with a 12-ring structure, it still suffers from strong steric and diffusion limitations from crystal sizes in the micrometer range in a number of catalytic reactions with participation of bulky molecules [15]. Thus, it is of prime importance to develop mesoporous Beta zeolite which can improve the catalytic activities substantially in various organic reactions involving large molecules compared with microporous Beta zeolites.

Three xylene isomers, namely $o$-xylene, $m$-xylene and $p$-xylene, are very important basic chemicals and find wide and various applications in chemical industry. Mixed xylenes are produced from petroleum by various catalytic reactions. However, as a result of important application to individual xylene isomers, it is necessary that mixed xylene is separated out through adsorption separation and isomerization reaction processes to obtain desired xylene isomers. In fact, the remarkable advances in $p$-xylene production from $m$-xylene isomerization using zeolite catalyst have been achieved over the last several decades [16-20]; meanwhile, the separation of xylene isomers through zeolite adsorbents has also gained considerable interest. The great success of zeolites as catalysts and adsorbents is exactly due to their unique shape selective properties from pore structure $[21,22]$. Shape-selective conversion and separation of 
xylenes over zeolites can be attributed the differences in the adsorptions and diffusivities of the three xylene isomers in the zeolite structures.

In preceding articles, we have used an organo-silylated nano- $\mathrm{SiO}_{2}$ as silicon source to synthesize mesoporous Beta zeolite with intracrystalline mesopores. In consideration of the essentiality for studying the adsorption and mass transport of molecules in the pores of nanoporous materials, where sorption and reaction sites are located, to understand catalytic and separation processes of organic molecules, in the present study, three xylene isomers were employed as probe molecules to explore the adsorption and diffusion behaviors of xylene isomers molecules on the mesoporous Beta zeolites by their adsorption isotherms and ZLC desorption curves. The impacts of mesopore in Beta zeolites on the adsorption and diffusion of xylene isomers with different molecular configuration will also be investigated.

\section{Results and Discussion}

\subsection{Characterization}

Figure 1 presents the X-ray powder diffraction (XRD) patterns of the four Beta zeolite samples. It is seen that the samples exhibit the diffraction peaks around 7.8[101] and 22.4[302], which are the characteristic peaks of BEA topology structure [1]. Compared to zeolite Beta-0, a slight decrease in the intensity of most peaks and broader reflections were observed for the mesoporous Beta zeolite samples. Nitrogen adsorption/desorption isotherms at $77 \mathrm{~K}$ on the four Beta zeolite samples and corresponding density functional theory (DFT) pore size distributions are displayed in Figure 2. Beta-0 sample exhibits a typical type I isotherm according to the International Union of Pure and Applied Chemistry (IUPAC) classification [23], reflecting solely microporous structure. However, the Beta-1, -2, -3 samples represent a steep uptake caused by the micropores filled at the low relative pressure region of $p / p_{0}<0.01$, followed by the gradual and continual rising curves and the hysteresis loops, indicating distinctly the presence of both micropores and mesopores. The pore sizes of the three mesoporous Beta zeolite samples mainly center in the range of 2-6 $\mathrm{nm}$ from the DFT pore size distribution curves. Table 1 listed the pore structural parameters of four Beta zeolite samples based on $\mathrm{N}_{2}$ adsorption/desorption isotherms. Mesoporous Beta-1, Beta-2, and Beta-3 possess an increasing sequence for mesopore volumes and external surface areas. Further, the typical scanning electron microscopy (SEM) and transmission electron microscope (TEM) images of the mesoporous Beta-3 zeolite sample are displayed in Figure 3. It is seen that the zeolite consists of particles with dimensions in the range of 400-600 nm made up of nanocrystals with sizes smaller than $100 \mathrm{~nm}$. These images also show mesoporous voids between the primary particles. Moreover, as showed in the TEM images, intracrystalline mesopores and lattice fringes of zeolite crystalline are well resolved in large scale through the zeolite particles, indicating the preservation of microporous structures and the presence of additional porosity within the crystals. 


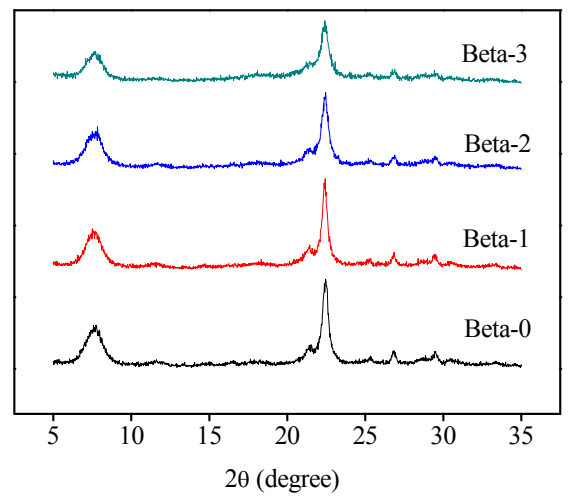

Figure 1. XRD patterns of Beta zeolite samples.
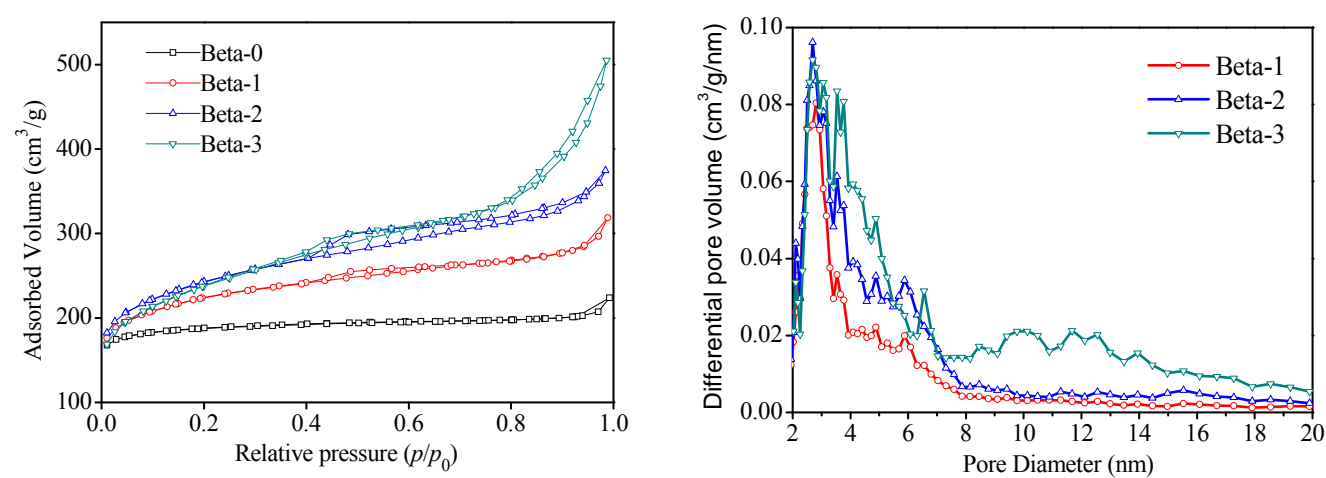

Figure 2. Nitrogen adsorption/desorption isotherms at $77 \mathrm{~K}$ and corresponding DFT pore size distributions of Beta zeolite samples.

Table 1. Pore structure parameters of Beta zeolite samples from $\mathrm{N}_{2}$ adsorption isotherms.

\begin{tabular}{cccccc}
\hline Sample & $\boldsymbol{S}_{\text {BET }}\left(\mathbf{m}^{2} / \mathbf{g}\right)$ & $\boldsymbol{S}_{\mathbf{m i c}}^{\mathbf{b}}\left(\mathbf{m}^{\mathbf{2}} / \mathbf{g}\right)$ & $\boldsymbol{S}_{\mathbf{e x t}}^{\mathbf{b}}\left(\mathbf{m}^{2} / \mathbf{g}\right)$ & $\boldsymbol{V}_{\mathbf{m i c}}{ }^{\mathbf{b}}\left(\mathbf{c m}^{\mathbf{3}} / \mathbf{g}\right)$ & $\boldsymbol{V}_{\text {meso }} \mathbf{c}\left(\mathbf{c m}^{\mathbf{3}} / \mathbf{g}\right)$ \\
\hline Beta-0 & 743 & 681 & 62 & 0.27 & 0.06 \\
Beta-1 & 814 & 591 & 223 & 0.25 & 0.18 \\
Beta-2 & 879 & 539 & 340 & 0.23 & 0.29 \\
Beta-3 & 851 & 392 & 459 & 0.17 & 0.51 \\
\hline
\end{tabular}

a Determined by the BET method. ${ }^{\mathrm{b}}$ Obtained from the $t$-plot method, $S_{\text {mic }}$ is micropore surface area; $S_{\text {ext }}$ is external surface area, $V_{\text {mic }}$ is micropore volume, ${ }^{\mathrm{c}} V_{\text {meso }}$ is mesopore volume ( $=V_{\text {total }}$ (total pore volume) $\left.-V_{\text {mic }}\right)$.
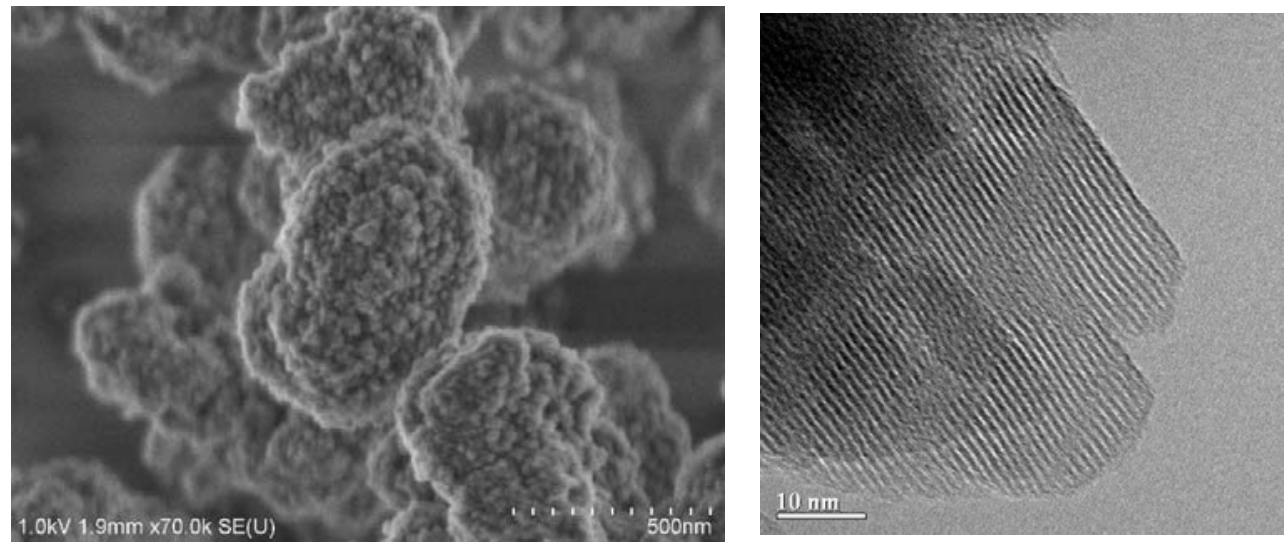

Figure 3. SEM/TEM of mesoporous Beta-3 zeolite sample. 


\subsection{Adsorption Results}

\subsubsection{Adsorption Equilibrium Isotherms}

Representative adsorption equilibrium isotherms of three xylene isomers on the microporous Beta- 0 and the mesoporous Beta-1,-2,-3 zeolite samples at $308 \mathrm{~K}$ are shown in Figure 4 . It is observed that the isotherms of three xylene isomers on the Beta- 0 display a sharp increase of adsorption capacities at low pressure region corresponding to micropore filling and then turn out to be a plateau at relative high pressures, which represent the typical characteristics of type-I adsorption isotherm. Compared to Beta- 0 , the adsorption isotherms of three xylene isomers on Beta-1,-2,-3 zeolites show a similar shape at first, however, the adsorption amount has a continual increase instead of a plateau as the pressure increases to relative higher pressure. This observation consists with the results of the $\mathrm{N}_{2}$ adsorption/desorption isotherms, indicating again the presence of mesopores in Beta-1,-2,-3 zeolites. Moreover, the increase of adsorption capacities with pressure on four Beta zeolite samples follows, obviously, the order of Beta- $0<$ Beta- $1<$ Beta- $2<$ Beta-3, which can be reasonably ascribed to the increase of the mesopore volume $\left(V_{\text {meso }}\right)$ caused by newly created mesopores.
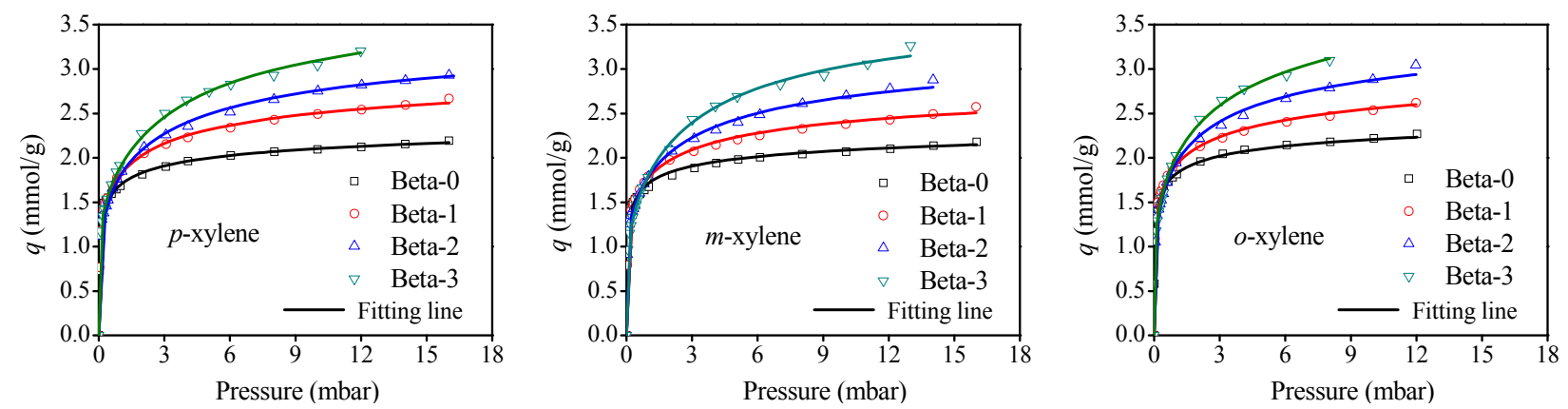

Figure 4. Adsorption isotherms of xylene isomers on Beta zeolite samples at $308 \mathrm{~K}$.

\subsubsection{Modeling of Equilibrium Isotherms}

The single-site Toth model and the dual-site Toth model were used to fit the adsorption equilibrium data for Beta-0 and Beta-1,-2,-3 zeolites, respectively. As illustrated in Figure 4, there is a good agreement between the symbols of experimental data and the solid lines obtained from the fitting models. All the fitting parameters of three xylene isomers on the four Beta zeolites are summarized in Tables 2 and 3.

The single-site Toth model can be expressed as follows [24]:

$$
q=\frac{q_{\mathrm{m}} b p}{\left(1+(b p)^{\mathrm{n}}\right)^{1 / \mathrm{n}}}
$$

where $q$ is the equilibrium adsorbed amount, $q_{\mathrm{m}}$ is the representation of the saturation adsorption capacity, $b$-value reflects the interaction between adsorbate and adsorbent, $n$ characterizes the surface heterogeneity. The farther $n$ is from 1 , more heterogeneous is the system. When $n$ is equal to 1 , the Toth model becomes the Langmuir model. Due to the change of adsorption environment for absorbate on mesoporous zeolites, the Toth isotherm model does not fit any more. In order to distinguish two categories of adsorption sites in the mesoporous Beta zeolite, the dual-site Toth model can be employed as follows: 


$$
q=\frac{q_{\mathrm{m}_{1}} b_{1} p}{\left(1+\left(b_{1} p\right)^{\mathrm{n}_{1}}\right)^{1 / \mathrm{n}_{1}}}+\frac{q_{\mathrm{m}_{2}} b_{2} p}{\left(1+\left(b_{2} p\right)^{\mathrm{n}_{2}}\right)^{1 / \mathrm{n}_{2}}}
$$

where the meaning of $q_{\mathrm{m}}, b, n$ is the same with that in above Toth model. The $q_{\mathrm{m} 1}, b_{1}$, and $n_{1}$ characterize parameters of adsorption site I, which represent the adsorption sites located inside the micropores, while $q_{\mathrm{m} 2}, b_{2}, n_{2}$ characterize parameters of adsorption site II which represent the adsorption sites located inside mesopores.

Table 2. Toth fitting parameters of xylene isomers on Beta-0.

\begin{tabular}{ccccc}
\hline $\boldsymbol{T}(\mathbf{K})$ & $\boldsymbol{q}_{\mathbf{m}}\left(\mathbf{m m o l} \cdot \mathbf{g}^{-\mathbf{1}}\right)$ & $\boldsymbol{b}\left(\mathbf{m b a r}^{-\mathbf{1}} \cdot \mathbf{1 0}^{\mathbf{3}}\right)$ & $\boldsymbol{n}$ & $\boldsymbol{R}^{\mathbf{2}}$ \\
\hline \multicolumn{5}{c}{$m$-xylene } \\
308 & 2.74 & 4.93 & 0.25 & 0.9945 \\
323 & 2.60 & 2.59 & 0.25 & 0.9815 \\
338 & 2.40 & 1.20 & 0.27 & 0.9782 \\
\hline \multicolumn{5}{c}{$p$-xylene } \\
308 & 2.79 & 2.20 & 0.26 & 0.9781 \\
323 & 2.64 & 1.88 & 0.26 & 0.9913 \\
338 & 2.44 & 0.99 & 0.27 & 0.9828 \\
\hline \multicolumn{5}{c}{$o$-xylene } \\
308 & 2.90 & 6.83 & 0.24 & 0.9894 \\
323 & 2.75 & 2.95 & 0.25 & 0.9880 \\
338 & 2.59 & 1.94 & 0.25 & 0.9888 \\
\hline
\end{tabular}

Table 3. Dual-site Toth fitting parameters of xylene isomers on Beta-1,-2,-3.

\begin{tabular}{|c|c|c|c|c|c|c|c|c|c|}
\hline Sample & Sorbate & $T(\mathrm{~K})$ & $q_{\mathrm{m} 1}\left(\mathrm{mmol} \cdot \mathrm{g}^{-1}\right)$ & $b_{1}\left(\mathrm{mbar}^{-1} \cdot 10^{3}\right)$ & $n_{1}$ & $q_{\mathrm{m} 2}\left(\mathrm{mmol} \cdot \mathrm{g}^{-1}\right)$ & $b_{2}\left(\mathrm{mbar}^{-1}\right)$ & $n_{2}$ & $R^{2}$ \\
\hline \multirow{9}{*}{ Beta-1 } & \multirow{3}{*}{$m$-xylene } & 308 & 1.98 & 4.53 & 0.35 & 1.13 & 1.37 & 0.49 & 0.9865 \\
\hline & & 323 & 1.80 & 2.24 & 0.31 & 1.01 & 0.92 & 0.53 & 0.9960 \\
\hline & & 338 & 1.67 & 0.98 & 0.32 & 0.90 & 0.36 & 0.63 & 0.9949 \\
\hline & \multirow{3}{*}{$p$-xylene } & 308 & 2.02 & 1.98 & 0.30 & 1.21 & 0.91 & 0.58 & 0.9948 \\
\hline & & 323 & 1.87 & 1.65 & 0.32 & 1.10 & 0.42 & 0.55 & 0.9979 \\
\hline & & 338 & 1.76 & 0.75 & 0.31 & 0.98 & 0.17 & 0.76 & 0.9976 \\
\hline & \multirow{3}{*}{$o$-xylene } & 308 & 2.13 & 6.52 & 0.35 & 1.34 & 1.68 & 0.41 & 0.9969 \\
\hline & & 323 & 1.91 & 2.49 & 0.30 & 1.25 & 1.32 & 0.44 & 0.9982 \\
\hline & & 338 & 1.80 & 1.61 & 0.31 & 1.05 & 0.66 & 0.49 & 0.9969 \\
\hline \multirow{9}{*}{ Beta-2 } & \multirow{3}{*}{$m$-xylene } & 308 & 1.64 & 4.21 & 0.32 & 1.78 & 0.54 & 0.70 & 0.9979 \\
\hline & & 323 & 1.49 & 1.97 & 0.38 & 1.66 & 0.22 & 0.82 & 0.9973 \\
\hline & & 338 & 1.36 & 0.54 & 0.38 & 1.51 & 0.18 & 0.73 & 0.9964 \\
\hline & \multirow{3}{*}{$p$-xylene } & 308 & 1.69 & 1.67 & 0.44 & 1.85 & 0.50 & 0.67 & 0.9992 \\
\hline & & 323 & 1.55 & 1.18 & 0.39 & 1.67 & 0.19 & 0.86 & 0.9981 \\
\hline & & 338 & 1.44 & 0.38 & 0.38 & 1.52 & 0.12 & 0.75 & 0.9973 \\
\hline & \multirow{3}{*}{$o$-xylene } & 308 & 1.74 & 4.70 & 0.38 & 1.97 & 0.88 & 0.59 & 0.9951 \\
\hline & & 323 & 1.63 & 2.14 & 0.32 & 1.83 & 0.42 & 0.64 & 0.9971 \\
\hline & & 338 & 1.51 & 1.21 & 0.35 & 1.73 & 0.27 & 0.59 & 0.9974 \\
\hline
\end{tabular}


Table 3. Cont.

\begin{tabular}{|c|c|c|c|c|c|c|c|c|c|}
\hline Sample & Sorbate & $T(K)$ & $q_{\mathrm{m} 1}\left(\mathrm{mmol} \cdot \mathrm{g}^{-1}\right)$ & $b_{1}\left(\operatorname{mbar}^{-1} \cdot 10^{3}\right)$ & $n_{1}$ & $q_{\mathrm{m} 2}\left(\mathrm{mmol} \cdot \mathrm{g}^{-1}\right)$ & $b_{2}\left(m b a r^{-1}\right)$ & $n_{2}$ & $R^{2}$ \\
\hline \multirow{9}{*}{ Beta-3 } & \multirow{3}{*}{$m$-xylene } & 308 & 1.35 & 3.64 & 0.35 & 2.53 & 0.45 & 0.78 & 0.9980 \\
\hline & & 323 & 1.20 & 1.36 & 0.50 & 2.40 & 0.19 & 0.99 & 0.9983 \\
\hline & & 338 & 1.05 & 0.27 & 0.53 & 2.25 & 0.12 & 0.99 & 0.9992 \\
\hline & \multirow{3}{*}{$p$-xylene } & 308 & 1.41 & 0.77 & 0.49 & 2.63 & 0.40 & 0.73 & 0.9985 \\
\hline & & 323 & 1.26 & 0.46 & 0.51 & 2.50 & 0.16 & 0.81 & 0.9982 \\
\hline & & 338 & 1.13 & 0.19 & 0.58 & 2.36 & 0.09 & 0.91 & 0.9984 \\
\hline & \multirow{3}{*}{$o$-xylene } & 308 & 1.51 & 3.92 & 0.34 & 2.95 & 0.68 & 0.59 & 0.9989 \\
\hline & & 323 & 1.40 & 1.76 & 0.37 & 2.77 & 0.25 & 0.72 & 0.9992 \\
\hline & & 338 & 1.27 & 0.63 & 0.40 & 2.63 & 0.16 & 0.68 & 0.9990 \\
\hline
\end{tabular}

Table 2 shows that the saturation adsorption capacities $q_{\mathrm{m}}$ of microporous sample Beta- 0 at each temperature follow an order of $m$-xylene $<p$-xylene $<o$-xylene. The order of $b$-values is $p$-xylene $<m$-xylene $<o$-xylene. Besides, the values of $n$, which characterize the system heterogeneity,

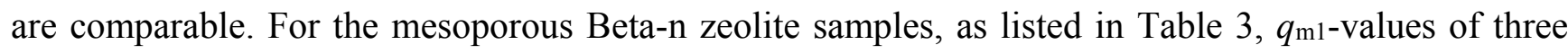
adsorbates decrease with the reduction of microporous volume in the order: Beta-1 > Beta-2 $>$ Beta-3 while $q_{\mathrm{m} 2}$-values have a growing trend with the increase of mesoporosity as expected. In addition, the total adsorption amounts of our samples at relative higher pressure are as follows: Beta- $0<$ Beta- $1<$ Beta- $<$ Beta-3, revealing a fact that the presence of mesopores provides more space for adsorption and it is helpful for the increase of adsorption capacity. It is easy to be seen that the values of $b_{1}, b_{2}$ derived from the dual-site Toth model for Beta-1,-2,-3 are smaller than $b$ derived from the Toth model for Beta- 0 and both $b_{1}$ and $b_{2}$ decrease with the increase of mesoporosity. Moreover, the $b_{1}$-values are much greater than $b_{2}$, which is similar to the result of mesoporous ZSM-5 [8], reflecting a weaker adsorbate-adsorbent interaction in mesopores than in micropores.

With regard to the saturate adsorption capacities $\left(q_{\mathrm{m}}\right.$ and $\left.q_{\mathrm{m} 1}, q_{\mathrm{m} 2}\right)$ of three xylene isomers, the order is: $o$-xylene $>p$-xylene $>m$-xylene. The reason why $o$-xylene has a greater adsorption amount can be divided into two characters. On the one hand, the packing configuration of $o$-xylene molecules, called "face-to-face" packing orientation, can pack much more closely in the channel of Beta zeolite samples than $p$-xylene molecules which have a "shoulder to shoulder" packing orientation [25,26]. This may contribute to the higher saturation capacities of $o$-xylene than $p$-xylene. On the other hand, the higher ortho adsorption also corresponds to the bigger $b$-values, which reflect the interaction between adsorbate and adsorbent. As listed in Tables 2 and 3 , the values of $b$ for Beta- 0 and $b_{1}, b_{2}$ for Beta-1,-2,-3 follow the same order of $o$-xylene $>m$-xylene $>p$-xylene. The result shows that $o$-xylene with a dipole moment interacts more strongly with the electric field of Beta zeolite than $p$-xylene without dipole moment. Thus, the ortho adsorption is further enhanced by electrostatic effects [27]. However, as to $m$-xylene, the electrostatic interaction seems to be only of secondary importance in the adsorption. The smallest adsorption capacity of $m$-xylene, which is inconsistent with the order of interactions, indicates that molecular configuration and size become the dominant factors in the adsorption of $m$-xylene on Beta zeolites. Apparently, there is only a slight difference in adsorption amounts between $p$-xylene and $m$-xylene, reflecting the combined effects of molecular configuration and electrostatic interaction. 


\subsubsection{Henry's Constants and Initial Heats of Adsorption}

Henry's constants $\left(K_{\mathrm{H}}\right)$ and the initial heats of adsorption, which are the characterizations of interaction force between the adsorbate and adsorbent at very low adsorption pressure, were calculated from the isotherm data in this work. According to the Virial equation:

$$
\ln (p / q)=-\ln \left(K_{\mathrm{H}}\right)+A_{1} q+A_{2} q^{2}+A_{3} q^{3}+\ldots
$$

where $A_{1}, A_{2}, A_{3}, \ldots$ are the virial coefficients. The plot of $\ln (p / q)$ as a function of $q$ should approach a line while the adsorption amount $q$ approximates to zero. The Henry's constant $\left(K_{\mathrm{H}}\right)$ could be directly calculated from the intercept $-\ln \left(K_{\mathrm{H}}\right)[28,29]$. Moreover, the heat of adsorption at zero coverage $Q_{\text {st }}$ were obtained from $1 / \mathrm{T}$ dependence of $\ln \left(K_{\mathrm{H}}\right)$ in terms of van't Hoff expression [30,31]:

$$
\ln K_{\mathrm{H}}=-\frac{Q_{\mathrm{st}}}{R T}+C
$$

The results are listed in Table 4. It is seen that Henry's constants and the initial heats of adsorption for three xylene isomers in the four samples follow the same order of Beta-3 $<$ Beta- $2<$ Beta- $1<$ Beta- 0 , indicating the weaker interaction between the adsorbate and adsorbent in mesoporous Beta zeolites. The difference in values of $K_{\mathrm{H}}$ between microporous Beta- 0 and mesoporous Beta-1,-2,-3 seems to be remarkable, corresponding to the variation of $b$-values and $b_{1}$-values discussed above.

The initial heats of adsorption for three xylene isomers in Beta- 0 , ranging from $55.5 \mathrm{~kJ} / \mathrm{moL}$ for $p$-xylene to $69.5 \mathrm{~kJ} / \mathrm{moL}$ for $o$-xylene, were higher than the values of $53.6 \mathrm{~kJ} / \mathrm{moL}$ for 2,2-dimethylbutane and $63.4 \mathrm{~kJ} / \mathrm{moL}$ for $n$-hexane in Beta zeolite [32]. The values of Henry's constants and the initial heats of adsorption for three xylene isomers go in order of $p$-xylene $<m$-xylene $<o$-xylene, which is accordance with the results of $b$ and $b_{1}$. This can be explained by the dipole moment $(D)$ of $p$-xylene, $m$-xylene and $o$-xylene, which are $0,0.33$ and 0.62 , respectively. The non-polar and the smallest molecule kinetic diameter of $p$-xylene result in the smallest Henry's constant value among three xylene isomers.

Table 4. Henry's constants $\left(K_{\mathrm{H}}\right)$ and heats of adsorption at zero coverage $\left(Q_{\mathrm{st}}\right)$ for xylene

\begin{tabular}{|c|c|c|c|c|}
\hline Sample & Sorbates & $T(\mathbf{K})$ & $K_{H}\left(\mathrm{mmol} / \mathrm{g} \mathrm{mbar} \cdot 10^{3}\right)$ & $Q_{\text {st }}(\mathrm{kJ} / \mathbf{m o L})$ \\
\hline \multirow{9}{*}{ Beta-0 } & \multirow{3}{*}{$p$-xylene } & 308 & 10.9 & \multirow{3}{*}{55.5} \\
\hline & & 323 & 4.35 & \\
\hline & & 338 & 1.53 & \\
\hline & \multirow{3}{*}{$m$-xylene } & 308 & 13.4 & \multirow{3}{*}{66.1} \\
\hline & & 323 & 4.38 & \\
\hline & & 338 & 1.68 & \\
\hline & \multirow{3}{*}{$o$-xylene } & 308 & 17.8 & \multirow{3}{*}{69.5} \\
\hline & & 323 & 4.94 & \\
\hline & & 338 & 1.77 & \\
\hline
\end{tabular}
isomers on Beta zeolite samples. 
Table 4. Cont.

\begin{tabular}{|c|c|c|c|c|}
\hline Sample & Sorbates & $T(\mathbf{K})$ & $K_{\mathrm{H}}\left(\mathrm{mmol} / \mathrm{g} \operatorname{mbar} \cdot 10^{3}\right)$ & $Q_{\text {st }}(\mathrm{kJ} / \mathrm{moL})$ \\
\hline \multirow{9}{*}{ Beta-1 } & \multirow{3}{*}{$p$-xylene } & 308 & 0.84 & \multirow{3}{*}{43.5} \\
\hline & & 323 & 0.41 & \\
\hline & & 338 & 0.19 & \\
\hline & \multirow{3}{*}{$m$-xylene } & 308 & 1.28 & \multirow{3}{*}{55.0} \\
\hline & & 323 & 0.47 & \\
\hline & & 338 & 0.21 & \\
\hline & \multirow{3}{*}{$o$-xylene } & 308 & 1.37 & \multirow{3}{*}{56.1} \\
\hline & & 323 & 0.51 & \\
\hline & & 338 & 0.22 & \\
\hline \multirow{9}{*}{ Beta-2 } & \multirow{3}{*}{$p$-xylene } & 308 & 0.11 & \multirow{3}{*}{35.1} \\
\hline & & 323 & 0.06 & \\
\hline & & 338 & 0.04 & \\
\hline & \multirow{3}{*}{$m$-xylene } & 308 & 0.19 & \multirow{3}{*}{42.8} \\
\hline & & 323 & 0.09 & \\
\hline & & 338 & 0.05 & \\
\hline & \multirow{3}{*}{$o$-xylene } & 308 & 0.31 & \multirow{3}{*}{43.6} \\
\hline & & 323 & 0.15 & \\
\hline & & 338 & 0.07 & \\
\hline \multirow{9}{*}{ Beta-3 } & \multirow{3}{*}{$p$-xylene } & 308 & 0.04 & \multirow{3}{*}{25.5} \\
\hline & & 323 & 0.03 & \\
\hline & & 338 & 0.02 & \\
\hline & \multirow{3}{*}{$m$-xylene } & 308 & 0.08 & \multirow{3}{*}{31.0} \\
\hline & & 323 & 0.05 & \\
\hline & & 338 & 0.03 & \\
\hline & \multirow{3}{*}{$o$-xylene } & 308 & 0.15 & \multirow{3}{*}{33.2} \\
\hline & & 323 & 0.07 & \\
\hline & & 338 & 0.05 & \\
\hline
\end{tabular}

\subsection{Diffusion Results}

ZLC diffusion experiments of xylene isomers ( $p$-xylene, $m$-xylene and $o$-xylene) on the four Beta zeolites with different mesoporosity were carried out at the high flow rate of $80 \mathrm{~mL} / \mathrm{min}$ and temperatures from $333 \mathrm{~K}$ to $373 \mathrm{~K}$. The partial pressure of three xylene isomers was maintained at 0.04 mbar, which are low enough to ensure the experiments were carried out within the Henry's law region. The fact that the system is controlled by kinetics was verified by measuring ZLC desorption curves of xylene isomers at two different flow rates under the same conditions. It turned out that two desorption curves have similar long time slopes, i.e., they are nearly parallel to each other in the tails [33]. The experimental desorption plots were fitted using Equations (5)-(7) to obtain the fitting parameters, $L, \beta$ and $D$ eff $/ R^{2}$. Representative experimental and theoretical ZLC curves of xylene isomers are showed in Figure 5. A good agreement 
is observed between the symbols represented experimental data and the solid lines obtained from fitting ZLC theoretical model with the goodness of fit $R^{2}>0.98$.

The correctness and effectiveness of the method was demonstrated by the above points.

From the desorption curves displayed in Figure 5, it is seen, obviously, that, under the same experimental conditions, the time spent for desorption to a certain $c / c 0$ reduce with the increase of mesoporosity in Beta zeolites, reflecting the enhancement of the speed of desorption by introduction of mesopores inside zeolites. For three different xylene isomers adsorbates, the desorption rates are in the order of $p$-xylene $>m$-xylene $>o$-xylene. A summary of the effective diffusion time constants $\left(D_{\text {eff }} / R^{2}\right)$ with parameters $L$ and $\beta$ extracted from the ZLC model fittings corresponding to Figure 5 are listed in Table 5. It is seen that the fitted $L$ values, which were used as a criterion for the ZLC model to guarantee that the desorption process is controlled by the kinetics [34,35], are all greater than 5 . The effective diffusivity values $\left(D_{\text {eff }} / R^{2}\right)$ of all sorbates are of the same magnitude around $10^{-4} \cdot \mathrm{s}^{-1}$, which is in reasonably good agreement with the reported results [36,37]. Figure 6 reveals the variation of the effective diffusion time constants for $p$-xylene, $m$-xylene and $o$-xylene with the mesopore volume at $333 \mathrm{~K}$. It can be seen that there is a similar trend for all adsorbates that the values of $D_{\text {eff }} / R^{2}$ approximate linearly increase with mesopore volumes of the Beta zeolites. The values of effective diffusion time constants $\mathrm{D}_{\text {eff }} / R^{2}$ for three xylene isomers increase with the mesoporosities of the Beta zeolites at the measured temperature. This confirms that the molecular transport in mesoporous Beta zeolites is obviously enhanced. In addition, the values of $\mathrm{D}_{\text {eff }} / R^{2}$ for the three xylene isomers in the four Beta zeolite samples at $373 \mathrm{~K}$ is in the following order: $p$-xylene $>m$-xylene $>o$-xylene, which shows the same trend as expected from their molecular kinetic diameter and Henry's constants. The favorable molecular configuration of adsorbate and weak interaction of adsorbate-adsorbent will be beneficial on the diffusion rate of adsorbates. Moreover, the relation of corresponding activation energy values calculated according the relationship between the temperature and diffusivity to mesopore volume are displayed in Figure 6. It is seen for the

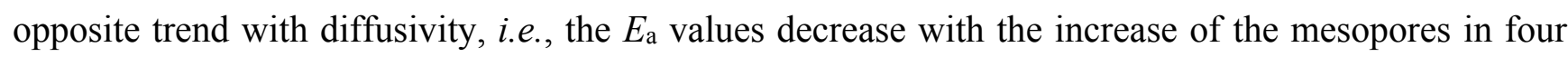
samples, which is similar to the previous reported results [8]. In addition, a significant downtrend can be seen for all adsorbates from Beta-0 to Beta-3 (e.g., from $24.7 \mathrm{~kJ} / \mathrm{moL}$ to $15.6 \mathrm{~kJ} / \mathrm{moL}$ for $p$-xylene, from $30.3 \mathrm{~kJ} / \mathrm{moL}$ to $20.9 \mathrm{~kJ} / \mathrm{moL}$ for $m$-xylene, from $31.1 \mathrm{~kJ} / \mathrm{moL}$ to $21.9 \mathrm{~kJ} / \mathrm{moL}$ for $o$-xylene, respectively). Such an observation reveals a general pattern that the activation energy involved in diffusion in a mesoporous zeolite would be relatively lower than that in a microporous zeolite.
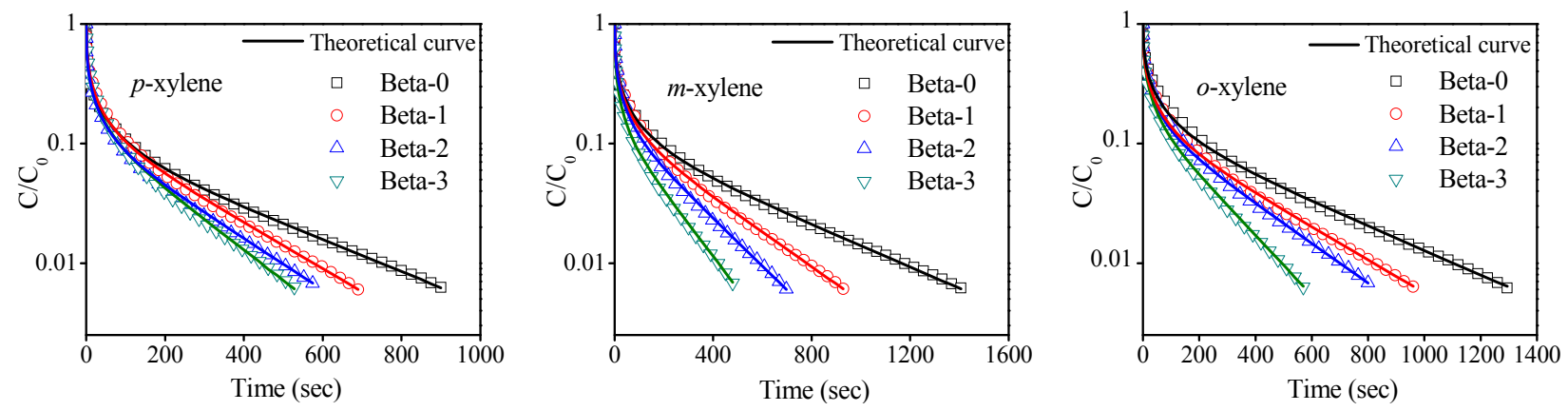

Figure 5. Experimental data (symbols) and theoretical ZLC curves (lines) for xylene isomers in Beta zeolite samples at $373 \mathrm{~K}$. 
Table 5. Zero length column (ZLC) fitting data for xylene isomers on Beta zeolite samples at $373 \mathrm{~K}$.

\begin{tabular}{cccc}
\hline Sample & $\boldsymbol{L}$ & $\boldsymbol{\beta}$ & $\boldsymbol{D}_{\text {eff }} / \boldsymbol{R}^{\mathbf{2}}\left(\mathbf{s}^{-\mathbf{1}} \cdot \mathbf{1 0}^{-\mathbf{4}}\right)$ \\
\hline \multicolumn{3}{c}{$p$-xylene } \\
\hline Beta-0 & 17.7 & 2.97 & 3.74 \\
Beta-1 & 15.6 & 2.94 & 5.18 \\
Beta-2 & 15.9 & 2.95 & 6.06 \\
Beta-3 & 13.1 & 2.91 & 7.48 \\
\hline \multicolumn{4}{c}{$m$-xylene } \\
\hline Beta-0 & 13.2 & 2.91 & 2.84 \\
Beta-1 & 12.9 & 2.90 & 4.26 \\
Beta-2 & 15.8 & 2.95 & 5.01 \\
Beta-3 & 16.9 & 2.96 & 6.85 \\
\hline \multicolumn{3}{c}{$o$-xylene } \\
\hline Beta-0 & 15.4 & 2.94 \\
Beta-1 & 13.4 & 2.91 & 2.73 \\
Beta-2 & 13.4 & 2.91 & 3.97 \\
Beta-3 & 14.3 & 2.93 & 6.64 \\
\hline
\end{tabular}

The above results provide objective evidence that the presence of mesopores in zeolite crystals can facilitate the transport of molecules by more paths, shortened diffusion length and the less diffusion resistance, attributed to the introduction of mesoporous into Beta zeolite.
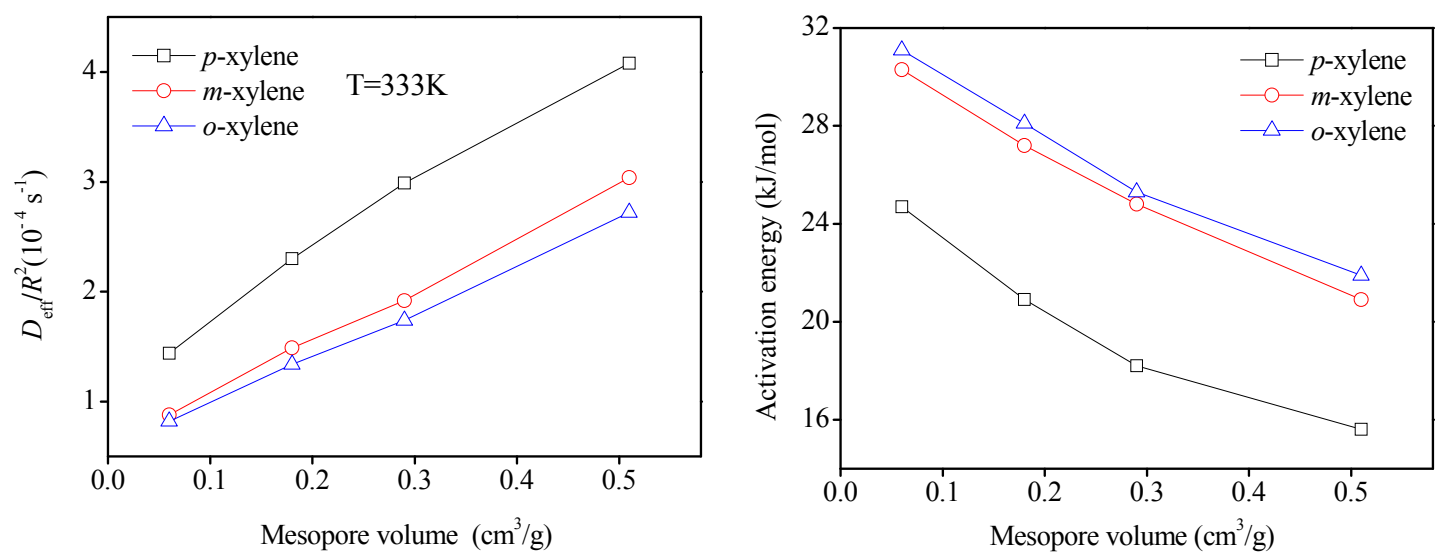

Figure 6. Effective diffusivities at different temperatures and activation energy of xylene isomers as the function of mesopore volume in Beta zeolite samples.

\section{Experimental Section}

\subsection{Materials and Characterization}

The mesoporous Beta zeolite samples used in this work were hydrothermally synthesized by employing organfunctioned nano-silica as silicon source, which was described in the previous paper [38]. Firstly, fumed silica (Aerosil 200, Degussa, Marl, NRW, Germany) was organic functioned with phenylaminopropyl-trimethoxysilane (PHAPTMS, Aldrich, Saint Louis, MO, USA), then obtained 
organo-silylated nano- $\mathrm{SiO}_{2}$ was used as silicon source, according to the molar composition of $\mathrm{Al}_{2} \mathrm{O}_{3}: 38$ org- $\mathrm{SiO}_{2}$ : $1.5 \mathrm{Na}_{2} \mathrm{O}: 10 \mathrm{TEAOH}: 532 \mathrm{H}_{2} \mathrm{O}$, three mesoporous Beta zeolite samples with different mesoporosities were synthesized by adjusting silanization degree of nano-silica, and coded as Beta- $n$ ( $n=1,2,3)$. The corresponding microporous Beta zeolite was synthesized by applying nano-silica without silanization under the same composition and conditions, and denoted Beta- 0 as a reference.

X-ray powder diffraction (XRD) patterns were examined using a SHIMADZU XRD-6000 diffractometer (Shimadzu, Nakagyo-ku, Kyoto, Japan) operating at $40 \mathrm{kV}$ and $30 \mathrm{~mA}$, which employed Ni-filtered and $\mathrm{Cu}-\mathrm{K} \alpha$ radiation with the step of $0.02^{\circ}$ and counting time of $10 \mathrm{~s}$. Nitrogen adsorption/desorption isotherms of the samples at $77 \mathrm{~K}$ were gained on a Quantachrome Quadrasorb SI gas adsorption analyzer (Quantachrome Instruments, Boynton Beach, FL, USA). The total surface area was obtained by using the BET (Brunauer-Emmett-Teller) equation, whereas the external surface area and micropore volume were calculated by the $t$-plot method [39]. The total pore volume was evaluated at $p / p=0.95$. The mesopore size distribution was derived from the adsorption branch of the isotherms using the density functional theory (DFT) method [40]. Scanning electron microscopy (SEM) and transmission electron microscope (TEM) images were obtained on a Hitachi S-4800II FE-SEM (Hitachi HighTechnolo-gies, Tokyo, Japan) and JEOL JEM-1011 microscope (Jeol, Tokyo, Japan), respectively.

\subsection{Adsorption Isotherms Measurements}

The adsorption isotherms measurements were carried out by an intelligent gravimetric analyzer (IGA-002, Hiden, Warrington, UK) with three xylene isomers as the representative probe adsorbates and four Beta zeolite samples as absorbents. The key component of this apparatus is a sensitive microbalance with the accuracy of $\pm 0.1 \mu \mathrm{g}$, which was used to record the changes in weight of the samples under the computer control. Before the sorption measurement, the zeolite sample about $50 \mathrm{mg}$ was activated under vacuum below $10^{-7}$ mbar and maintained at $673 \mathrm{~K}$ for $300 \mathrm{~min}$ to remove the impurities and moisture until the sample weight keeping constant. In the process of measurement, the vapor of the sorbate was gradually introduced into the sample chamber until the set pressure value was obtained. On reaching the adsorption equilibrium under the set point, the weight change was recorded by the computer software and the vapor pressure was increased to the next designed pressure. Finally, a complete adsorption isotherm was drawn at a certain pressure range. The measurements of adsorption isotherms for xylene isomers on Beta zeolites in this work were conducted in the pressure range of 0-20 mbar and temperature range of $308-338 \mathrm{~K}$, respectively.

\subsection{ZLC Measurement and Theory}

The ZLC method was first proposed by Eic and Ruthven in the late 1980s [41]. Since then, it had become one of the most common methods to measure the intracrystalline diffusion coefficients [42-45]. This method has the advantage of eliminating the intrusion of extraneous heat and mass transfer resistances. The ZLC system was detailedly depicted in [41]. The experimental apparatus is similar to conventional gas chromatography; however, the packed column in gas chromatograph (GC) is replaced by a ZLC column, which is loaded with a very thin layer of sample sandwiched between two porous sintered metal disks. In accordance with the ZLC theory, the sorbate concentration was controlled under the very low relative partial pressures to guarantee the experiments were carried out within the linear region of the 
adsorption isotherms, i.e., within the Henry's law region. The effluent stream concentration of ZLC was monitored online by the flame ionization detector.

Assuming the adsorption occurring in a very thin layer of zeolite spherical crystals within the linear region of adsorption equilibrium at the very low adsorbate partial pressure, as well as neglecting the hold-up in the ZLC bed and the perfect mixing throughout the ZLC system, the relationship between relative effluent concentration $c / c_{0}$ and time $t$ is given by references $[41,46]$ :

$$
\frac{\mathrm{c}}{\mathrm{c}_{0}}=2 \mathrm{~L} \sum_{\mathrm{n}=1}^{\infty} \frac{\exp \left(-\frac{\beta_{\mathrm{n}}{ }^{2} \mathrm{D}_{\text {eff }} \mathrm{t}}{\mathrm{R}^{2}}\right)}{\left[\beta_{\mathrm{n}}{ }^{2}+\mathrm{L}(\mathrm{L}-1)\right]}
$$

where $D_{\text {eff }} / R^{2}$ is the effective diffusion time constant, $R$ is the particle radius, $L$ is a dimensionless parameter and the eigenvalues $\beta_{\mathrm{n}}$ are given by the roots of the auxiliary equation:

$$
\beta_{\mathrm{n}} \cot \beta_{\mathrm{n}}+L-1=0
$$

and

$$
\mathrm{L}=\frac{1}{3} \frac{\mathrm{FR}^{2}}{\mathrm{KV}_{\mathrm{s}} \mathrm{D}_{\text {eff }}}
$$

where $F$ is purge flow rate, $V_{\mathrm{s}}$ is the volume of adsorbent and $K$ is the dimensionless Henry's law constant.

Based on the above relationships, $D_{\text {eff }} / R^{2}$ and $L$ values can be extracted by fitting Equations (5)-(7) to the experimental ZLC data applying the full range method by matlab software [47].

Additionally, the relationship between the temperature and diffusivity is described by the Arrhenius form [48]:

$$
\mathrm{D}=\mathrm{D}_{0} \exp \left(-\mathrm{E}_{\mathrm{a}} / \mathrm{R}_{g} \mathrm{~T}\right)
$$

From measurements at three different temperatures, estimates for the activation energy $E_{\text {a }}$ of diffusion may be calculated by

$$
\mathrm{E}_{\mathrm{a}}=R_{\mathrm{g}} T^{2}\left(\frac{\partial \ln D_{\mathrm{eff}} / R^{2}}{\partial T}\right)
$$

where $R_{\mathrm{g}}$ is the ideal gas constant, the activation energy for diffusion $E_{\mathrm{a}}$ can be calculated from the slope of line which is made according to $\ln D_{\text {eff }} / R^{2}$ and $1 / T$ [49].

\section{Conclusions}

The adsorption and diffusion properties of three xylene isomers on Beta zeolites with different mesoporosities were discussed to investigate the effects of mesopores in zeolites for molecules with different kinetic diameter, molecular configuration and dipole. The adsorption isotherms of three xylene isomers on mesoporous Beta zeolites presented the shapes of type IV, reflecting the introduction of secondary mesoporosity with together $\mathrm{N}_{2}$ adsorption. The enhanced adsorption capacities, reduced values of Henry's constants $K_{\mathrm{H}}$ and initial heats of adsorption $Q_{\mathrm{st}}$ with increasing mesoporosity are observed. The successful fittings of adsorption isotherms of three xylene isomers on mesoporous Beta zeolites by the dual-site Toth model reflect the differences of adsorption for xylene isomers on microporous 
and mesoporous surfaces, a much weaker sorbent-sorbate interaction over the surface of mesopore than that over micropore surface are found. $K_{\mathrm{H}}$ and $Q_{\text {st }}$ follow the order of $p$-xylene $<m$-xylene $<o$-xylene, non-polar and smaller kinetic diameter could account for the smallest $K_{\mathrm{H}}$ and $Q_{\text {st }}$ value of $p$-xylene. The ZLC desorption curves of three xylene isomers on the Beta zeolites, obtained at same experimental condition, present the enhanced desorption speed with increasing mesoporosity inside zeolite crystals. The effective diffusion time constants $\left(D_{\text {eff }} / R^{2}\right)$ derived from desorption curves display the increased trend with the increase of mesopore volume, whereas activation energies decrease with the increase of mesoporosity. The results reflect the improved effect of mesopore on mass transfer in zeolite, due to more paths, shortened diffusion length and the less diffusion resistance in mesoporous zeolite relative to microporous zeolite. The diffusivity of three xylene isomers follow the order of $o$-xylene $<m$-xylene $<p$-xylene, which is ascribed to the smaller molecular kinetic diameter and weaker interaction of adsorbate-adsorbent for $p$-xylene relative to $m$-xylene and $o$-xylene.

\section{Acknowledgments}

This work was supported by the National Natural Science Foundation of China (Grant No. 51272169).

\section{Author Contributions}

Jinghong Ma and Ruifeng Li designed the experiments. Aixia Song and Duo Xu conducted the experiments. Duo Xu, Aixia Song, Jinghong Ma and Ruifeng Li analyzed the data. Jinghong Ma wrote the first draft of the manuscript, which was then revised by all other authors.

\section{Conflicts of Interest}

The authors declare no conflict of interest.

\section{References}

1. Baerlocher, C.; McCusker, L.B.; Olson, D.H. Atlas of Zeolite Framework Types; Elsevier Science: Amsterdam, The Netherlands, 2007; p.73.

2. Ackley, M.W.; Rege, S.U.; Saxena, H. Application of natural zeolites in the purification and separation of gases. Microporous Mesoporous Mater. 2003, 61, 25-42.

3. Degnan, T.F., Jr. Applications of zeolites in petroleum refining. Top. Catal. 2000, 13, 349-356.

4. Christensen, C.H.; Johannsen, K.; Törnqvist, E.; Schmidt, I.; Topsøe, H. Mesoporous zeolite single crystal catalysts: Diffusion and catalysis in hierarchical zeolites. Catal. Today 2007, 128, 117-122.

5. Verboekend, D.; Pérez-Ramírez, J. Design of hierarchical zeolite catalysts by desilication. Catal. Sci. Technol. 2011, 1, 879-890.

6. Choi, M.; Cho, H.S.; Srivastava, R.; Venkatesan, C.; Choi, D.H.; Ryoo, R. Amphiphilic organosilane-directed synthesis of crystalline zeolite with tunable mesoporosity. Nat. Mater. 2006, 5, 718-723.

7. Tao, Y.; Kanoh, H.; Abrams, L.; Kaneko, K. Mesopore-modified zeolites: Preparation, characterization, and applications. Chem. Rev. 2006, 106, 896-910. 
8. Zhao, H.; Ma, J.; Zhang, Q.; Liu, Z.; Li, R. Adsorption and diffusion of n-heptane and toluene over mesoporous ZSM-5 zeolites. Ind. Eng. Chem. Res. 2014, 53, 13810-13819.

9. Lee, S.; Kim, H.; Choi, M. Controlled decationization of X zeolite: Mesopore generation within zeolite crystallites for bulky molecular adsorption and transformation. J. Mater. Chem. A 2013, 1, 12096-12102.

10. Gu, F.N.; Wei, F.; Yang, J.Y.; Lin, N.; Lin, W.G.; Wang, Y.; Zhu, J.H. New strategy to synthesis of hierarchical mesoporous zeolites. Chem. Mater. 2010, 22, 2442-2450.

11. Bonilla, M.R.; Valiullin, R.; Kärger, J.; Bhatia, S.K. Understanding adsorption and transport of light gases in hierarchical materials using molecular simulation and effective medium theory. J. Phys. Chem. C 2014, 118, 14355-14370.

12. Groen, J.C.; Zhu, W.; Brouwer, S.; Huynink, S.J.; Kapteijn, F.; Moulijn, J.A.; Pérez-Ramírez, J. Direct demonstration of enhanced diffusion in mesoporous ZSM-5 zeolite obtained via controlled desilication. J. Am. Chem. Soc. 2007, 129, 355-360.

13. Zhao, L.; Shen, B.; Gao, J.; Xu, C. Investigation on the mechanism of diffusion in mesopore structured ZSM-5 and improved heavy oil conversion. J. Catal. 2008, 258, 228-234.

14. Newsam, J.M.; Treacy, M.M.; Koetsier, W.T.; de Gruyter, C.B. Structural characterization of zeolite beta. Proc. R. Soc. Lond. A 1988, 420, 375-405.

15. Brito, A.; Borges, M.E.; Otero, N. Zeolite Y as a heterogeneous catalyst in biodiesel fuel production from used vegetable oil. Energy Fuels 2007, 21, 3280-3283.

16. Perez-Pariente, J.; Sastre, E.; Fornes, V.; Martens, J.A.; Jacobs, P.A.; Corma, A. Isomerization and disproportionation of m-xylene over zeolite $\beta$. Appl. Catal. 1991, 69, 125-137.

17. Ratnasamy, P.; Bhat, R.N.; Pokhriyal, S.K.; Hegde, S.G.; Kumar, R. Reactions of aromatic hydrocarbons over zeolite $\beta$. J. Catal. 1989, 119, 65-70.

18. Llopis, F.J.; Sastre, G.; Corma, A. Xylene isomerization and aromatic alkylation in zeolites NU-87, SSZ-33, $\beta$, and ZSM-5: Molecular dynamics and catalytic studies. J. Catal. 2004, 227, $227-241$.

19. Byun, Y.; Jo, D.; Shin, D.N.; Hong, S.B. Theoretical investigation of the isomerization and disproportionation of $\mathrm{m}$-Xylene over medium-pore zeolites with different framework topologies. ACS Catal. 2014, 4, 1764-1776.

20. Fernandez, C.; Stan, I.; Gilson, J.P.; Thomas, K.; Vicente, A.; Bonilla, A.; Pérez-Ramírez, J. hierarchical ZSM-5 zeolites in shape-selective xylene isomerization: Role of mesoporosity and acid site speciation. Chem. A Eur. J. 2010, 16, 6224-6233.

21. Dehkordi, A.M.; Khademi, M. Adsorption of xylene isomers on Na-BETA zeolite: Equilibrium in batch adsorber. Microporous Mesoporous Mater. 2013, 172, 136-140.

22. Rasouli, M.; Yaghobi, N.; Allahgholipour, F.; Atashi, H. Para-xylene adsorption separation process using nano-zeolite Ba-X. Chem. Eng. Res. Des. 2014, 92, 1192-1199.

23. Sing, K.S. Reporting physisorption data for gas/solid systems with special reference to the determination of surface area and porosity (Recommendations 1984). Pure Appl. Chem. 1985, 57, 603-619.

24. Do, D.D. Adsorption Analysis: Equilibria and Kinetics; Imperial College Press: London, UK, $1998 ;$ p.64. 
25. Cavalcante, C.L., Jr.; Azevêdo, D.C.; Souza, I.G.; Silva, A.C.M.; Alsina, O.L.; Lima, V.E.; Araujo, A.S. Sorption and diffusion of p-xylene and o-xylene in aluminophosphate molecular sieve $\mathrm{AlPO}_{4-11 .}$ Adsorption 2000, 6, 53-59.

26. Chiang, A.S.; Lee, C.K.; Chang, Z.H. Adsorption and diffusion of aromatics in AIPO4-5. Zeolites 1991, 11, 380-386.

27. Peralta, D.; Barthelet, K.; Pérez-Pellitero, J.; Chizallet, C.; Chaplais, G.; Simon-Masseron, A.; Pirngruber, G.D. Adsorption and separation of xylene isomers: CPO-27-Ni vs HKUST-1 vs NaY. J. Phys. Chem. C 2012, 116, 21844-21855.

28. Ruthven, D.M.; Kaul, B.K. Adsorption of n-hexane and intermediate molecular weight aromatic hydrocarbons on LaY zeolite. Ind. Eng. Chem. Res. 1996, 35, 2060-2064.

29. Silva, J.A.; Rodrigues, A.E. Sorption and diffusion of n-pentane in pellets of 5A zeolite. Ind. Eng. Chem. Res.1997, 36, 493-500.

30. Vavlitis, A.P.; Ruthven, D.M.; Loughlin, K.F. Sorption of n-pentane, n-octane, and n-decane in 5A zeolite crystals. J. Colloid Interface Sci. 1981, 84, 526-531.

31. Saha, D.; Deng, S. Adsorption equilibrium, kinetics, and enthalpy of $\mathrm{N}_{2} \mathrm{O}$ on zeolite 4A and $13 \mathrm{X}$. J. Chem. Eng. Data 2010, 55, 3312-3317.

32. Bárcia, P.S.; Silva, J.A.; Rodrigues, A.E. Adsorption equilibrium and kinetics of branched hexane isomers in pellets of Beta zeolite. Microporous Mesoporous Mater. 2005, 79, 145-163.

33. Liu, Z.; Fan, W.; Xue, Z.; Ma, J.; Li, R. Diffusion of n-alkanes in mesoporous 5A zeolites by ZLC method. Adsorption 2013, 19, 201-208.

34. Brandani, S. Effects of nonlinear equilibrium on zero length column experiments. Chem. Eng. Sci. 1998, 53, 2791-2798.

35. Brandani, S.; Jama, M.A.; Ruthven, D.M. ZLC measurements under non-linear conditions. Chem. Eng. Sci. 2000, 55, 1205-1212.

36. Ruthven, D.M.; Eic, M.; Richard, E. Diffusion of $\mathrm{C}_{8}$ aromatic hydrocarbons in silicalite. Zeolites 1991, 11, 647-653.

37. Brandani, S.; Jama, M.; Ruthven, D. Diffusion, self-diffusion and counter-diffusion of benzene and p-xylene in silicalite. Microporous Mesoporous Mater. 2000, 35, 283-300.

38. Zhang, Q.; Ming, W.; Ma, J.; Zhang, J.; Wang, P.; Li, R. De novo assembly of mesoporous beta zeolite with intracrystalline channels and its catalytic performance for biodiesel production. J. Mater. Chem. A 2014, 2, 8712-8718.

39. Rouquerol, F.; Rouquerol, J.; Sing. K. Adsorption by Powders and Porous Solids; Academic Press: San Diego, CA, USA, 1999; p.267.

40. Landers, J.; Gor, G.Y.; Neimark, A.V. Density functional theory methods for characterization of porous materials. Colloids Surf. A 2013, 437, 3-32.

41. Eic, M.; Ruthven, D.M. A new experimental technique for measurement of intracrystalline diffusivity. Zeolites 1988, 8, 40-45.

42. Gunadi, A.; Brandani, S. Diffusion of linear paraffins in NaCaA studied by the ZLC method. Microporous Mesoporous Mater. 2006, 90, 278-283.

43. Ruthven, D.M. Diffusion of aromatic hydrocarbons in silicalite/HZSM-5. Adsorption 2007, 13, 225-230. 
44. Thang, H.V.; Malekian, A.; Eić, M.; On, D.T.; Kaliaguine, S. Diffusive characterization of large pore mesoporous materials with semi-crystalline zeolitic framework. Stud. Surf. Sci. Catal. 2003, 146, 145-148.

45. Malekian, A.; Vinh-Thang, H.; Huang, Q.; Eic, M.; Kaliaguine, S. Evaluation of the main diffusion path in novel micro-mesoporous zeolitic materials with the zero length column method. Ind. Eng. Chem. Res. 2007, 46, 5067-5073.

46. Hufton J.R.; Ruthven D.M. Diffusion of light alkanes in silicalite studied by the zero length column method. Ind. Eng. Chem. Res.1993, 32, 2379-2386.

47. Han, M.; Yin, X.; In, Y.; Chen, S. Diffusion of aromatic hydrocarbon in ZSM-5 studied by the improved zero length column method. Ind. Eng. Chem. Res. 1999, 38, 3172-3175.

48. Cavalcante, C.L., Jr.; Silva, N.M.; Souza-Aguiar, E.F.; Sobrinho, E.V. Diffusion of paraffins in dealuminated Y mesoporous molecular sieve. Adsorption 2003, 9, 205-212.

49. Gobin, O.C.; Huang, Q.; Vinh-Thang, H.; Kleitz, F.; Eic, M.; Kaliaguine, S. Mesostructured silica SBA-16 with tailored intrawall porosity part 2: Diffusion. J. Phys. Chem. C 2007, 111, 3059-3065.

(C) 2015 by the authors; licensee MDPI, Basel, Switzerland. This article is an open access article distributed under the terms and conditions of the Creative Commons Attribution license (http://creativecommons.org/licenses/by/4.0/). 